\title{
Corrigendum: Observational study of land-surface-cloud-atmosphere coupling on daily timescales
}

\author{
Alan K. Betts ${ }^{1 *}$, Raymond Desjardins ${ }^{2}$, Anton C. M. Beljaars ${ }^{3}$ and Ahmed Tawfik ${ }^{4,5 t}$ \\ ${ }^{1}$ Atmospheric Research, Pittsford, VT, USA, ${ }^{2}$ Agriculture and Agri-Food Canada, Ottawa, ON, Canada, ${ }^{3}$ The European \\ Centre for Medium-Range Weather Forecasts, Reading, UK, ${ }^{4}$ The National Center for Atmospheric Research, Boulder, CO, \\ USA, ${ }^{5}$ Center for Ocean-Land-Atmosphere Studies, George Mason University, Fairfax, VA, USA
}

Keywords: land-atmosphere coupling, diurnal climate, Canadian Prairies, cloud radiative forcing, hydrometeorology

\section{A Corrigendum on}

Observational study of land-surface-cloud-atmosphere coupling on daily timescales by Betts, A. K., Desjardins, R., Beljaars, A. C. M., and Tawfik, A. (2015). Front. Earth Sci. 3:13. doi: 10.3389/feart.2015.00013

In the original article, there was an error in the leading constant in the cold season $\mathrm{LW}_{\mathrm{n}}$ regression in Equation (18b). The correct equation is

\section{OPEN ACCESS}

Edited and reviewed by: Pierre Gentine,

Columbia University, USA

*Correspondence: Alan K. Betts

akbetts@aol.com

${ }^{\dagger}$ Present Address: Ahmed Tawfik,

NCAR, Boulder, CO, USA

Specialty section:

This article was submitted to

Atmospheric Science,

a section of the journal

Frontiers in Earth Science

Received: 21 March 2016

Accepted: 20 April 2016

Published: 03 May 2016

Citation:

Betts AK, Desjardins R, Beljaars ACM and Tawfik A (2016) Corrigendum:

Observational study of land-surface-cloud-atmosphere coupling on daily timescales. Front. Earth Sci. 4:56. doi: 10.3389/feart.2016.00056

$$
\begin{aligned}
\mathrm{LW}_{\mathrm{n}}= & -112.2( \pm 9.8)+43.5( \pm 2.8) \mathrm{OPAQ}_{\mathrm{m}}+26.8( \pm 2.5) \mathrm{OPAQ}_{\mathrm{m}}^{2}+0.29( \pm 0.02) \mathrm{RH}_{\mathrm{m}} \\
& -1.02( \pm 0.03) \mathrm{T}_{\mathrm{m}}(18 \mathrm{~b})
\end{aligned}
$$

The authors apologize for the mistake. This error does not change the scientific conclusions of the article in any way. However, this error was carried over to a following paper, where it led to a y-axis offset for $\mathrm{LW}_{\mathrm{n}}$ and $\mathrm{R}_{\mathrm{n}}$ in Figure 5 of Betts and Tawfik (2016a). A corrigendum has been posted also for this paper (Betts and Tawfik, 2016b).

\section{AUTHOR CONTRIBUTIONS}

All authors listed, have made substantial, direct and intellectual contribution to the work, and approved it for publication.

\section{REFERENCES}

Betts, A. K., and Tawfik, A. B. (2016a). Annual climatology of the diurnal cycle on the Canadian Prairies. Front. Earth Sci. 4:1. doi: $10.3389 /$ feart.2016.00001

Betts, A. K., and Tawfik, A. B. (2016b). Corrigendum: Annual climatology of the diurnal cycle on the Canadian Prairies. Front. Earth Sci. 4:53. doi: 10.3389/feart.2016.00053

Conflict of Interest Statement: The authors declare that the research was conducted in the absence of any commercial or financial relationships that could be construed as a potential conflict of interest.

Copyright $\odot 2016$ Betts, Desjardins, Beljaars and Tawfik. This is an open-access article distributed under the terms of the Creative Commons Attribution License (CC BY). The use, distribution or reproduction in other forums is permitted, provided the original author(s) or licensor are credited and that the original publication in this journal is cited, in accordance with accepted academic practice. No use, distribution or reproduction is permitted which does not comply with these terms. 